\title{
Granulocytosis and increased adhesion molecules after resistive loading of the diaphragm
}

\author{
X. Wang, T-X. Jiang, J.D. Road, D.M. Redenbach and W.D. Reid
}

ABSTRACT: Upregulation of endothelial cell adhesion molecules, followed by an influx of granulocytes and macrophages, can contribute to exertion-induced skeletal muscle injury. The purpose of this study was to quantify circulating leukocyte subsets, diaphragm injury and infiltrating leukocyte subsets, and surface expression of vascular cell adhesion molecule (VCAM)1 and intracellular adhesion molecule (ICAM)-1 in the diaphragm after inspiratory resistive loading (IRL).

Eight New Zealand white rabbits underwent $1.5 \mathrm{~h}$ of IRL and seven control rabbits underwent a sham procedure. Blood samples, taken at baseline and 2, 6, 12, 24, 48 and $72 \mathrm{~h}$ after the onset of IRL or sham, showed that band cell counts had increased at $6 \mathrm{~h}$ post-IRL. Point counting of haematoxylin and eosin-stained cross-sections, sampled at $72 \mathrm{~h}$ post-IRL, showed greater injury in diaphragms from IRL rabbits compared with controls. Immunohistochemical processing showed increased expression of ICAM-1 and VCAM-1, and higher granulocyte and macrophage counts in IRL diaphragms than control diaphragms. Macrophages were the predominant inflammatory cells.

Increased intracellular adhesion molecule-1 and vascular cell adhesion molecule-1 expression, and infiltration of granulocytes and macrophages may contribute to inspiratory resistive loadinginduced diaphragm injury.

KEYWORDS: Cell adhesion molecules, circulating leukocytes, lung diseases, respiratory muscles

$\mathbf{A}$ cute exercise increases the circulating pool of leukocytes, the magnitude of which is relative to the intensity and duration of the exercise $[1,2]$. The number of circulating nonspecific immune cells, including mobilisation of neutrophils from the marginated pools into the circulation, is mediated by the exercise intensity-dependent secretion of stress hormones, such as catecholamines [3], cortisol [4, $5]$ and growth hormone [3, 4]. Catecholaminemediated flushing of neutrophils from the marginated pools into the circulation occurs through the shear force of exercise-induced haemodynamics. Cortisol and various cytokines induce early release of neutrophils from the bone marrow [3], which is reflected by an increase in band cells after exhaustive exercise [3, 4].

Exertion-induced muscle injury can be initiated by unaccustomed exercise, resulting in structural disruption of muscle fibres during and postexercise [5]. This is followed by neutrophil infiltration and release of myocellular proteins, such as creatine kinase $(\mathrm{CK})$ and myoglobin, into the circulation [4, 5]. Marked systemic neutrophilia with a leftward shift (reflective of increased band cells) and enhanced capacity of neutrophils to release reactive oxygen species have been documented after endurance exercise and were correlated positively with subsequent efflux of CK $[4,6,7]$. This suggests that after stressful exercise, mobilised and primed neutrophils may be important mediators of exertioninduced muscle damage [4]. Furthermore, several investigators have recently implicated indices of acute inflammation to be a mechanism for Z-line disruption, myocellular protein release and delayed onset muscle soreness after eccentric exercise [8-10].

Local inflammation in injured muscle can include complement activation, upregulation of adhesion molecule expression on leukocytes and endothelium with subsequent migration, and infiltration of blood leukocytes into the affected tissue $[9,11]$. The selective recruitment of leukocytes into traumatised tissue in a defined sequence [11] involves the combined action of multiple cell

\section{AFFILIATIONS}

School of Rehabilitation Sciences, James Hogg iCapture Centre for Cardiovascular and Pulmonary Research, Vancouver Coastal Health Authority, Respiratory Division, University of British Columbia, Vancouver, BC, Canada.

\section{CORRESPONDENCE}

W.D. Reid

School of Rehabilitation Sciences

T325-2211 Wesbrook Mall

Vancouver

BC Canada V6T 2B5

Fax: 16048227624

E-mail: wdreid@interchange.ubc.ca

Received:

September 082004

Accepted after revision:

July 262005

SUPPORT STATEMENT

This study was supported by British Columbia Lung Association

(Canada).

European Respiratory Journal Print ISSN 0903-1936

Online ISSN 1399-3003 
adhesion molecules, including intracellular adhesion molecule (ICAM)-1 and vascular cell adhesion molecule (VCAM)-1, that are expressed on the endothelium and which bind to LFA-1 and VLA-4 expressed on leukocytes, respectively [12, 13].

Similar to exertion-induced injury of the limb muscles, marked diaphragm injury has been shown after $1.5 \mathrm{~h}$ of intensive inspiratory resistive loading (IRL) [14, 15]. The IRL in this animal model is $\sim 60-70 \%$ of the maximal load, which might be similar to the load experienced by patients with chronic obstructive pulmonary disease (COPD) or asthma during an acute exacerbation. The role of adhesion molecules and the response of circulating and intramuscular populations of leukocytes have not yet been characterised in this model. The postulation presented here is that diaphragm injury induced by IRL increases circulating leukocytes, and upregulates ICAM-1 and VCAM-1 expression on endothelium, which promotes recruitment of neutrophils and macrophages/monocytes into the injured muscle. The purpose of this study was to quantify circulating leukocyte subsets, the expression of VCAM-1 and ICAM-1 in the diaphragm, infiltrating leukocyte subsets, and diaphragm injury after IRL.

\section{METHODS}

Ethical approval was provided by the University of British Columbia Committee on Animal Care (Canada). The study conformed to the animal care guidelines of the Canadian Council on Animal Care. Two groups of New Zealand White rabbits ranging 3.5-4.5 kg were studied: IRL $(\mathrm{n}=8)$ and control $(\mathrm{n}=7)$ groups.

\section{Protocol}

The protocol for IRL has been described previously [14, 15]. Briefly, after intravenous thiopental anaesthesia and intubation, the IRL rabbits underwent $1.5 \mathrm{~h}$ of IRL at an airway opening pressure of $\sim 45 \mathrm{cmH}_{2} \mathrm{O}$, and control rabbits underwent the identical procedure without resistive loading. Rabbits were then extubated and allowed to recover.

Blood was sampled (0.5-mL samples) before anaesthesia for IRL (baseline), and at 2, 6, 12, 24, 48 and $72 \mathrm{~h}$ after the beginning of IRL for total and differential leukocyte counts. Total leukocyte and differentials, including band cell counts, were tabulated from coded Wright-stained smears, for which observers were blinded to group assignment codes.

At $72 \mathrm{~h}$ post-IRL, rabbits were euthanised. The costal diaphragm was excised, trimmed and quick-frozen in isopentane cooled in liquid nitrogen, and stored at $-70^{\circ} \mathrm{C}$ for histological and immunohistochemical studies.

\section{Histological and immunohistochemical studies}

Transverse sections of diaphragm samples were stained with haematoxylin and eosin (H\&E) to quantify muscle damage. For immunohistochemical processing, $10-\mu \mathrm{m}$ transverse sections of diaphragm samples were fixed in acetone for $10 \mathrm{~min}$. Sections were incubated at room temperature with each of the optimally diluted primary antibodies for $1 \mathrm{~h}$. The following mouse anti-rabbit antibodies were used in the present study: RbM2 (macrophage/monocyte antibody; dilution 1:100; ICN Biomedical, Inc., Irvine, CA, USA); NP-5 (neutrophil defensin 5; dilution 1:50; Hycult Biotechnology, Uden, The
Netherlands); monoclonal antibody to T-helper lymphocytes (dilution 1:1,200; Spring Valley Lab., Woodbine, MD, USA); monoclonal antibody to T-suppressor lymphocytes (dilution 1:400; Spring Valley Lab.); Rb 2/3 (ICAM, dilution 1:20); and $\mathrm{Rb} 1 / 9$ (VCAM; dilution 1:25; both $\mathrm{Rb} 2 / 3$ and $\mathrm{Rb} 1 / 9$ were kind gifts from M. Cybulsky, University of Toronto, Toronto, Canada). After rinsing with TBS, the specimens were treated with rabbit anti-mouse IgG (1:20) for $30 \mathrm{~min}$. Control sections were incubated with the nonspecific mouse $\operatorname{IgG}_{1}$. Specific binding was detected by incubation with 1:50 monoclonal mouse alkaline phosphatase-antialkaline phosphatase complex (DAKO, Ontario, Canada) for $30 \mathrm{~min}$, followed by a new fuschin-base red substrate solution.

\section{Quantification of diaphragm injury, leukocyte infiltration and adhesion molecules}

All slides of muscle cross-sections were coded so observers were blinded to group assignment. Twenty images of each muscle cross-section processed for either $\mathrm{H} \& \mathrm{E}$ or specific antibodies for the different leukocytes were captured using a $40 \times$ objective and $0.6 \times$ reduction lens attached to a microscope and digital camera.

Diaphragm injury was quantified by computerised point counting of H\&E-stained diaphragm cross-sections using Image Pro Plus Software (MediaCybernetics, Silver Spring, MD, USA). Points projected on the H\&E-stained cross-sections were assigned to categories of normal diaphragm, abnormal diaphragm and connective tissue, and were expressed as percentages of total points counted for each animal as described previously [14].

Labelled intramyofibre and interstitial leukocytes were counted using a rectangular unbiased counting frame superimposed on the image as described previously [16]. Labelled cells inside the blood vessels were excluded. The area of the counting frame was $0.0901 \mathrm{~mm}^{2}$ and was calibrated at the

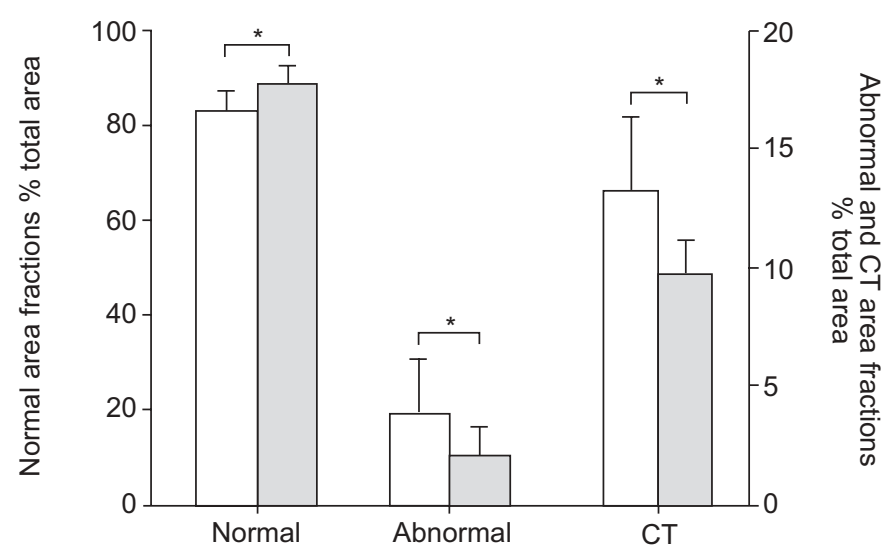

FIGURE 1. Area fractions of normal diaphragm, abnormal diaphragm and connective tissue $(C T)$ in inspiratory resistive loading (IRL; $\square ; n=8$ ) and control ( $\square$; $n=7$ ) groups. The area fractions of the abnormal diaphragm and CT in the IRL group were significantly greater than those in the control group, respectively. The area fraction of the normal diaphragm in the $\mathrm{IRL}$ group was significantly smaller than the control values. ${ }^{*}: p<0.05$ 

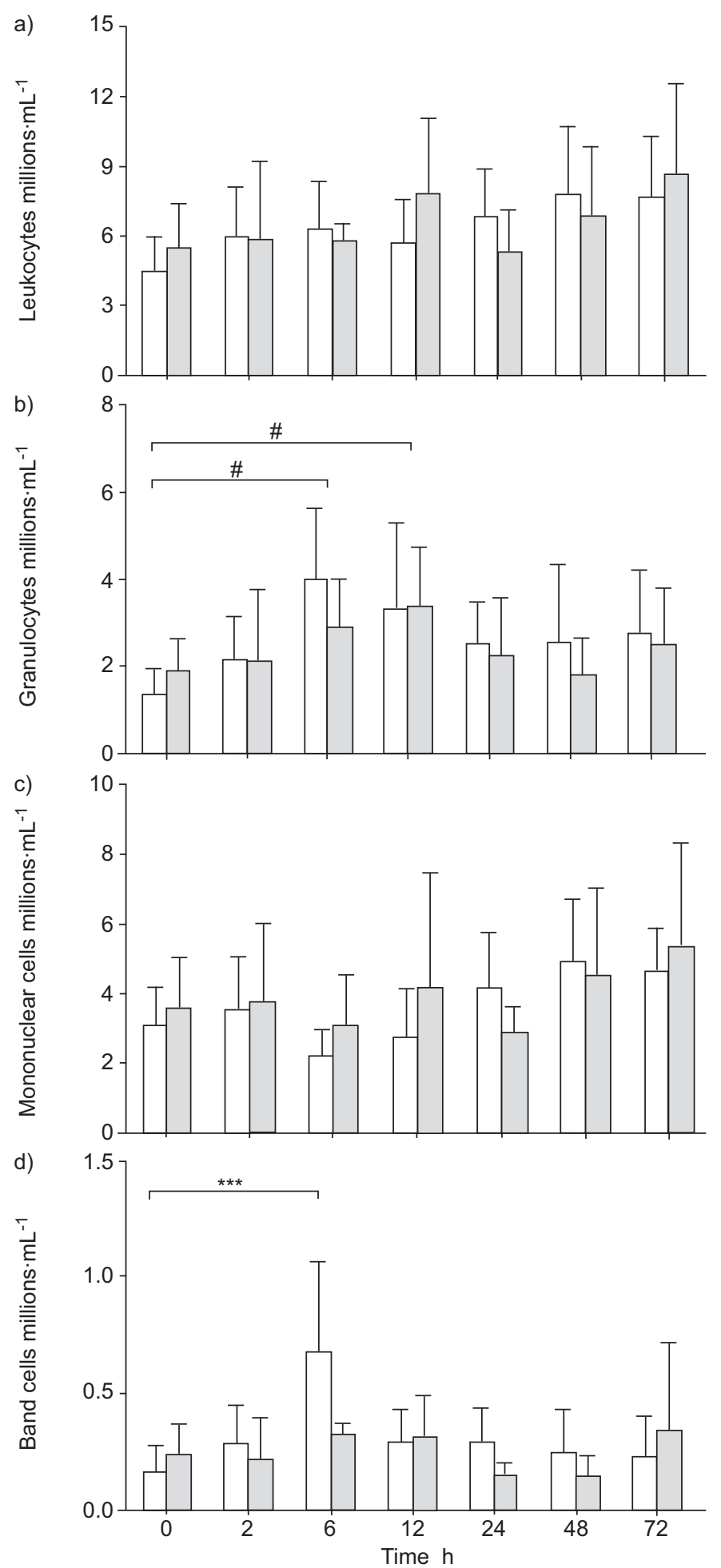

FIGURE 2. Circulating leukocyte and subset counts in inspiratory resistive loading (IRL; $\square ; n=8$ ) and control ( $\square ; n=7$ ) groups: a) concentration of total circulating leukocytes over time (no differences between groups or over time were found); $b$ ) concentration of circulating granulocytes over time (at 6 and $12 \mathrm{~h}$ the circulating granulocytes of both groups had significantly increased compared with baseline, ${ }^{\#}$ : $\left.p<0.002\right)$; c) concentration of circulating mononuclear cells over time (no differences between groups or over time were found); and d) circulating band cells over time (the band cells in IRL group significantly increased at $6 h$, and then decreased thereafter, ${ }^{* * *}: p<0.001$ ). beginning of each session. The number of leukocytes was expressed per $\mathrm{mm}^{2}$.

The number of ICAM-1- and VCAM-1-positive blood vessels per $\mathrm{mm}^{2}$ were counted, including vessels consistent with the size of capillaries, in 15-20 fields of diaphragm cross-sectional images per sample at a magnification of $\times 400(40 \times$ objective, $10 \times$ eyepiece). The expression of ICAM- 1 was also assessed by staining intensity [17]: $0=$ no staining; $1=$ mild; $2=$ moderate; and $3=$ strong. The extent of VCAM- 1 was also assessed by the amount of the endothelial staining [18]: $0=$ no staining; $1=\leqslant 25 \%$ of the vessel circumference showed positive staining; $2=25-50 \%$ of the vessel circumference was positive; $3=50-75 \%$ of the vessel circumference was positive; and $4=\geqslant 75 \%$ of the vessel circumference was positive.

\section{Statistics}

Staining intensities of ICAM-1 and VCAM-1 were expressed as medians. All the other data were expressed as mean \pm SD. Circulating leukocytes and differential data were analysed by two-way repeated-measures ANOVA. If interaction was significant, one-way repeated-measure ANOVA procedures, followed by the Tukey HSD post hoc test, were performed to determine the effect of time on the dependent variables for each level of the intervention (control or IRL) [19]. Differences in diaphragm leukocyte concentrations between groups were analysed by independent-sample t-tests. The ICAM-1 intensity score between groups was tested using the Mann-Whitney U-test.

\section{RESULTS}

\section{Diaphragm injury}

Light microscopic examination of the H\&E-stained diaphragm cross-sections revealed diaphragm injury in the IRL group, including necrotic diaphragm fibres, fibre degeneration, and an influx of inflammatory cells in the necrotic diaphragm fibres and interstitium. Point counting H\&E cross-sections showed an $85 \%$ higher area fraction of abnormal diaphragm and a $36 \%$ higher area fraction of connective tissue in the diaphragm of the IRL group compared with control values ( $p<0.05$; fig. 1 ). Conversely, the area fraction of the normal diaphragm in the IRL group was significantly smaller than control values $(\mathrm{p}<0.05$; fig. 1).

\section{Changes in circulating leukocyte and subset counts}

The concentration of total circulating leukocytes did not change over time across groups from baseline to $72 \mathrm{~h}$. Granulocyte counts, however, increased across groups at the 6- and 12-h time points compared with baseline $(\mathrm{p}<0.002$; fig 2.), then decreased to baseline values thereafter. Band cell counts were higher at $6 \mathrm{~h}$ across groups and a significant interaction was shown from the two-way ANOVA. In order to interpret the interaction, one-way repeated-measures ANOVAs were performed on band cell data from each group. Band cells were higher in the IRL group at $6 \mathrm{~h}$ post-IRL when compared with baseline, and decreased thereafter $(p<0.001$; fig. 2). Band cell counts did not change over time in the control group. Mononuclear cell counts did not change across groups over time. 


\section{Expression of VCAM-1 and ICAM-1}

The expression of VCAM-1 and ICAM-1 is displayed in figure 3 .

ICAM-1 positively stained vessel counts per field tended to be higher in the IRL group when compared with control group values (table 1), but the trend did not reach statistical significance. The IRL group showed increased staining intensity for ICAM-1 in the endothelium of diaphragm blood vessels compared with the control values $(\mathrm{p}<0.05$, table 2$)$.

VCAM-1 positively stained vessel counts per field were higher in the IRL group when compared to control group values $(\mathrm{p}<0.05$, table 1$)$. Five out of eight IRL diaphragms from the IRL group showed VCAM-1-stained endothelial cells in venules and veins. There were no VCAM-1 positive-stained vessels in the remaining three IRL and seven control diaphragms (tables 1 and 2). The counts of positively stained vessels for the five IRL rabbits ranged $0.45-2.98$ vessels $\cdot \mathrm{mm}^{-2}$.
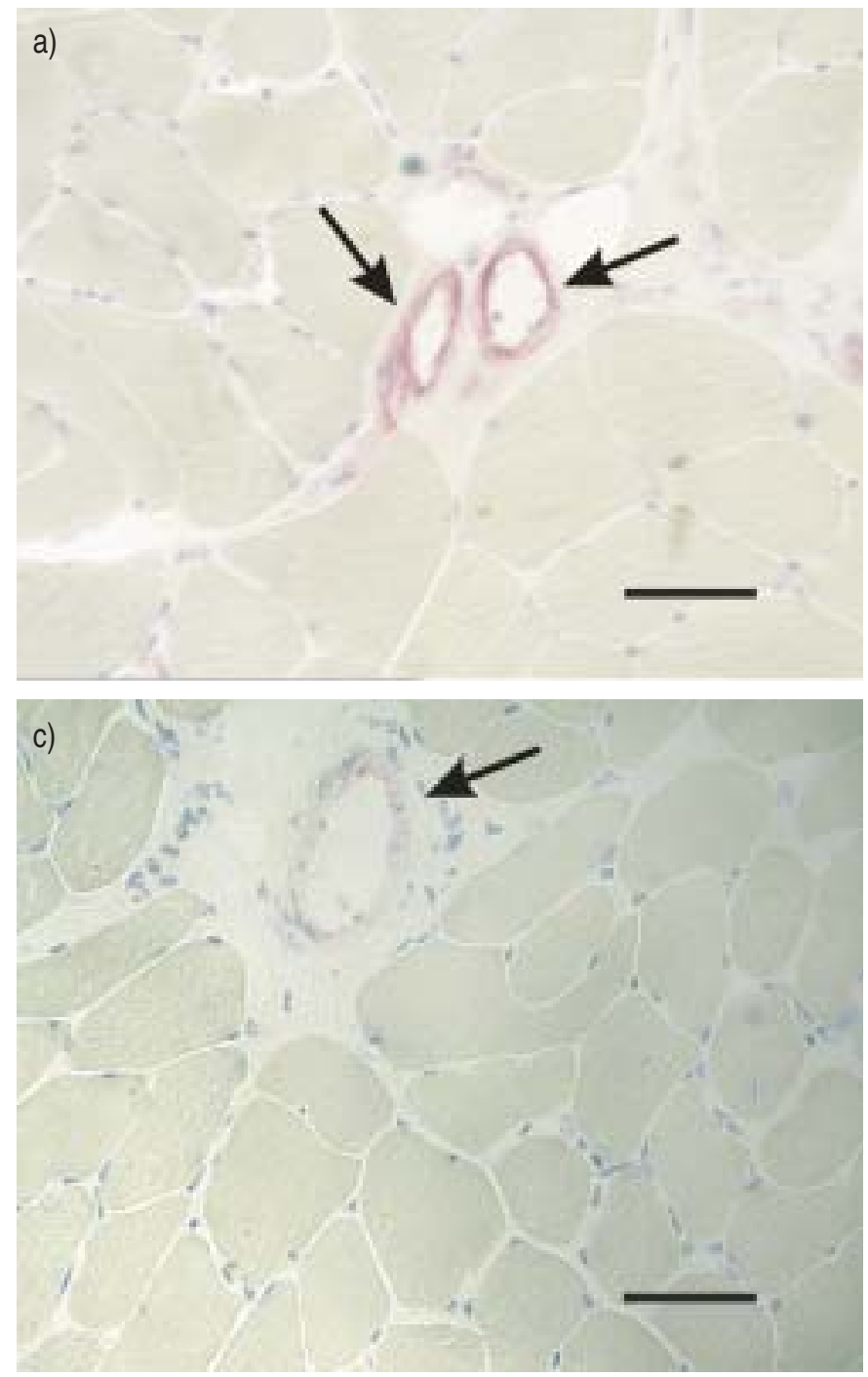

Inflammatory cell concentrations in diaphragm after IRL

Macrophages were the predominant inflammatory cell type found in the diaphragm of the IRL group. Macrophage and neutrophil counts in the diaphragms were significantly higher in the IRL group when compared with the control group $(\mathrm{p}<0.05$, fig. 4).

\section{DISCUSSION}

The unique findings of this study are that IRL in rabbits induced an increase in circulating band cells, signifying bone marrow stimulation. Three days after the loading, increased expression of the adhesion molecules, ICAM-1 and VCAM-1, in diaphragm vessels was accompanied by increased macrophage and neutrophil recruitment into the injured muscle. This is the first study to show this sequence of inflammatory events after exertion-induced diaphragm injury, and it is speculated that these leukocytes contribute to the diaphragm muscle injury seen after resistive loading.
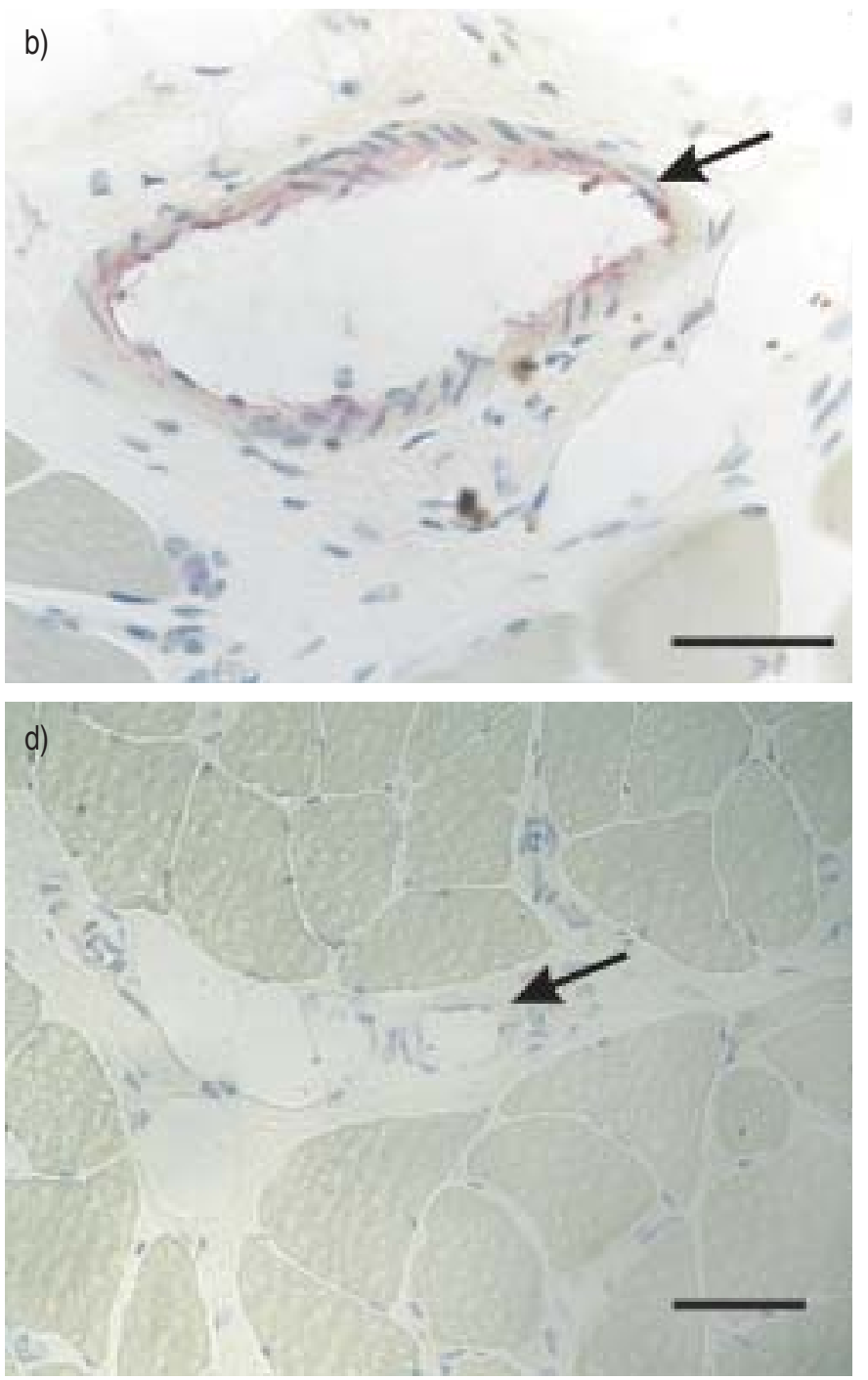

FIGURE 3. Intracellular adhesion molecule (ICAM)-1 is strongly positive (a) and vascular cell adhesion molecule (VCAM)-1 is expressed (b) on the endothelium of vessels from inspiratory resistive loading diaphragms. ICAM-1 is weakly expressed on the endothelium of vessels from control rabbit (c), whereas expression of VCAM-1 on vessels from control diaphragms is not apparent (d). Arrows indicate vessels in diaphragm cross-sections. Scale bars $=50 \mu \mathrm{m}$. 


\begin{tabular}{|c|c|c|}
\hline TABLE 1 & \multicolumn{2}{|c|}{$\begin{array}{l}\text { Intracellular adhesion molecule (ICAM)- } 1 \text { and } \\
\text { vascular cell adhesion molecule (VCAM)-1 } \\
\text { expression on blood vessels in the diaphragm in } \\
\text { inspiratory resistive loading (IRL) and control } \\
\text { groups }\end{array}$} \\
\hline & IRL & Control \\
\hline ICAM-1 & $4.43 \pm 2.72^{*}$ & $2.48 \pm 1.36$ \\
\hline VCAM-1 & $1.20 \pm 1.32 *$ & 0 \\
\hline
\end{tabular}

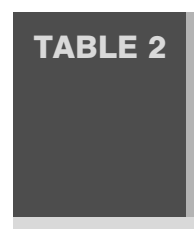

Staining intensity of intracellular adhesion molecule (ICAM)-1 and amount of vascular cell adhesion molecule (VCAM)- 1 of vascular endothelia in the diaphragm in inspiratory resistive loading (IRL) and control groups

\begin{tabular}{cccc}
\hline ICAM-1 & VCAM-1 & $\begin{array}{c}\text { Abnormal } \\
\text { diaphragm }\end{array}$ \\
\hline IRL & & & \\
1 & $3(0-3)$ & $2(0-4)$ & 3.1 \\
2 & $1(0-2)$ & $0(0)$ & 4.8 \\
3 & $0(0-2)$ & $0(0)$ & 2.4 \\
4 & $1(0-2)$ & $0(0-2)$ & 3.1 \\
5 & $2(0-2)$ & $0(0)$ & 2.3 \\
6 & $1(0-3)$ & $0(0-2)$ & 5.5 \\
7 & $3(0-3)$ & $3(0-4)$ & 5.1 \\
8 & $2(0-3)$ & $2(0-3)$ & 2.8 \\
Control & & & \\
9 & $1(0-2)$ & $0(0)$ & 2.3 \\
10 & $0(0-2)$ & $0(0)$ & 2.9 \\
11 & $0(0-1)$ & $0(0)$ & 4 \\
12 & $0(0-2)$ & $0(0)$ & 1.1 \\
13 & $1(0-2)$ & $0(0)$ & 0.7 \\
14 & $0(0-3)$ & $0(0)$ & 1.1 \\
15 & $0(0-2)$ & $0(0)$ & 0.9 \\
\hline
\end{tabular}

Data are presented as median (range) or \% total. The staining intensity of ICAM-1 in the diaphragm of the IRL group was significantly greater than control values.

Granulocytes increased across animals at 6 and $12 \mathrm{~h}$, and band cell counts increased at $6 \mathrm{~h}$ post-IRL; however, the concentration of total circulating leukocytes across groups did not change over time. The increase in circulating neutrophils that accompanied the increased band cell counts implicates bone marrow release as the main source of immature circulating neutrophils in addition to mobilisation of marginated pools [20]. In the presence of increased granulocyte and band cell counts, the constant counts of total circulating leukocytes after IRL were probably due to a fall in lymphocyte concentrations. This finding is consistent with previous findings after strenuous endurance exercise [21, 22]. Physical exerciseinduced transient redistribution of peripheral blood is

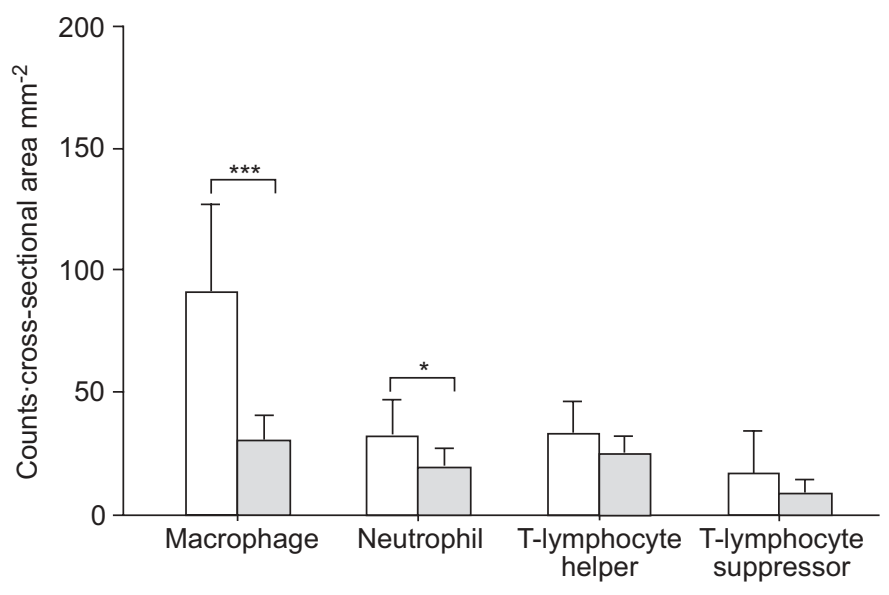

FIGURE 4. Inflammatory cells counts in the diaphragm after inspiratory resistive loading (IRL; $\square$ ) or sham ( $\square$ ). Macrophage and neutrophil counts per $\mathrm{mm}^{2}$ in the diaphragm of $\mathrm{IRL}$ group were significantly greater than control values. *: $p<0.05$; ***: $p<0.001$.

characterised by a granulocytosis accompanied by lymphocytosis during exercise, followed by a more pronounced granulocytosis accompanied by lymphopenia after exercise [22]. WigERNAEs et al. [21] reported a continuous increase in neutrophils during active recovery with a fall in lymphocytes, which kept the total leukocytes constant at 120 min following a 60 -min bout of uphill running at $83 \%$ of maximal oxygen uptake. In the present study, mononuclear cell counts tended to decrease in the IRL group at $6 \mathrm{~h}$ post-IRL compared with baseline, but the decrease did not reach a significant level, which could be due to the small change and small sample. Based on the means, variances and differences shown in the circulating mononuclear cells of the IRL group, a sample size of $n=45$ would be required to achieve a power of 0.80 with a standardised difference of 0.83 .

Neutrophil mobilisation after the control surgery and IRL appears to be a nonspecific stress response and is probably mediated by stress hormones, such as catecholamines [3, 23] and cortisol $[4,5]$. The significant increase in band cells after IRL, however, is a more specific injury rather than a stress response indicative of bone marrow release [23]. Band cell release could be attributed to growth hormone and cytokines induced by the exertional stimulus [3,4]. Strenuous resistive breathing has been shown to induce increases in plasma interleukin (IL)-1 $\beta$, IL-6 and tumour necrosis factor- $\alpha$, which have been shown to be significantly blunted by antioxidants $[24,25]$. IL-6, IL-8 and granulocyte colony-stimulating factor may be associated with delayed-onset neutrophil mobilisation from the bone marrow reserve [1, 4]. Previously, IL-6 and macrophage colony-stimulating factor responses were shown to be positively correlated with neutrophil mobilisation after exercise [20].

In the current study, it was found that resistive loading of the inspiratory muscles by small muscle mass exercise alters leukocyte trafficking. This is consistent with a recent report by NEMET et al. [26] who demonstrated that $10 \mathrm{~min}$ of low-intensity unilateral wrist flexion exercise can increase the concentration of inflammatory mediators, growth factors and 
circulating leukocytes in the control arm and not just in the exercising arm. They concluded that the increase in circulating leukocytes and inflammatory cytokines may have resulted from stimulation of the autonomic nervous system rather than the local working muscles.

In the present study, the magnitude of the increase in band cells after IRL was much less compared with that reported after marathon running [20]. This is probably due to the much smaller muscle group recruited during IRL relative to running. Neutrophilia, and especially band neutrophil mobilisation was positively correlated to intensity of strenuous exercise as reflected by the exercise percentage maximal oxygen uptake, supporting the suggestion of SUZUKI et al. [4, 20] that magnitude of the workload may be a determinant of the amount of neutrophil mobilisation from the bone marrow reserve. The present finding of a smaller circulating leukocyte redistribution after IRL was not surprising, because the small muscle mass of the inspiratory muscles does not increase exercise oxygen uptake to the same magnitude as marathon running. Although oxygen consumption was not measured in the current study, oxygen uptake during high and medium IRL in a dog model was 1.29- and 1.17-times the resting oxygen uptake, respectively [27]. In contrast, whole body exercise at $60 \%$ of maximal oxygen uptake represents an estimated sixfold increase over resting oxygen uptake.

In the present study, the time course of no increase in circulating leukocytes and granulocytes during the exercise stimulus was somewhat different than reported data after other exercise stimuli. The primary reason why there was no early increase in circulating leukocytes during the IRL stimulus while the rabbits were anesthetised ( $2 \mathrm{~h}$ time point) was probably due to the inhibitory effects of anaesthetics on neutrophil function and kinetics. Thiopental, the anaesthetic used in the current study, decreases human neutrophil chemotaxis in a dose-dependent manner at clinically relevant concentrations [28]. Previous work in the current authors' laboratory has shown that circulating leukocytes counts are lower in rabbits while anesthetised with a variety of different agents (unpublished data), which may be due in part to anaesthetic-induced decreases in stress and circulating catecholamines that result in increased margination of neutrophils in the lung capillaries. Although these anaesthetic effects have not been published, BOXER et al. [29] found that a $\beta$-antagonist, propranolol, will largely, but not completely, block the increase in adrenaline-mediated increase in circulating neutrophils.

The present study examined ICAM-1 and VCAM-1 expression and leukocyte subsets invasion in the diaphragm at $72 \mathrm{~h}$ postIRL in this model, based on the previous time course studies that showed the greatest amount of muscle injury and inflammation 3 days after the exercise stimulus [30-34], including one study that showed a peaking of neutrophils and macrophages at 3 days [34]. One previous IRL study has demonstrated that overt diaphragm injury, occurring at $72 \mathrm{~h}$ post-IRL, was accompanied by increased inflammatory cells in the diaphragm [14]. The leukocyte-endothelial cell interaction is an early step in the cascade of events that leads to the development of the inflammatory response and cellular extravasation. It was proposed that the recruitment of granulocytes to the damaged diaphragm is supported by the widely accepted paradigm that inflammatory stimuli activate the endothelial cells of these vessels to express adhesion molecules and chemokines, which physically engage circulating leukocytes and promote their adhesion to these vessels. The adhesion molecules, ICAM-1 and VCAM-1, are normally expressed and upregulated during inflammation, or expressed only on activated endothelial cells in response to inflammatory stimuli [35].

The strong expression of ICAM-1 and VCAM-1 in the injured diaphragm supports the postulation that interaction between these molecules and leukocytes is a major factor in the migration of activated leukocytes into the inflamed diaphragm $[36,37]$. As expected, no VCAM-1 was expressed on the endothelium of vessels in the control group, but positive staining was observed following IRL.

The findings of increased expression of ICAM-1 and VCAM-1 in the diaphragm after IRL were similar to those reported after other types of exercise and in muscle diseases. Previous studies have shown that exercise can induce increases in soluble (s) ICAM-1 levels in the plasma [12, 38]. Акімото et al. [12] measured plasma concentrations of sICAM-1 before and after three types of exercise. The plasma concentration of sICAM-1, 1 day after a $42-\mathrm{km}$ run or a downhill run, was significantly increased, whereas high-intensity bicycle ergometer exercise did not influence plasma concentrations of sICAM-1. It was concluded that plasma concentrations of sICAM-1 increase only after exercise associated with muscle damage [12]. Immunohistopathological studies have shown the upregulation of ICAM-1 and VCAM-1 in endothelial cells and infiltrating cells in biopsies of muscle tissue from patients with polymyositis and dermatomyositis [39, 40], and with critical illness polyneuropathy and myopathy [18]. Tissue expression of VCAM-1 is associated with muscle injury and pronounced inflammation in polymyositis [40]. To the current authors' knowledge, no studies thus far have examined the role of adhesion molecules in the diaphragm after IRL.

Macrophages were the predominant inflammatory cell type in the diaphragm at 72-h post-IRL. Leukocytes, initially neutrophils and subsequently monocytes/macrophages, have been identified in areas with muscle injury after eccentric exercise [10]. Neutrophils, the first inflammatory cell type to appear in injured muscle [11, 34, 41], have been suggested to have a role in both injury and regeneration of injured muscle. Although no direct in vivo evidence exists, neutrophils have been hypothesised to delay muscle regeneration by exacerbating the initial injury and/or by injuring myotubes through the release of free radicals and proteases [8]. In addition, neutrophils could facilitate muscle regeneration by removing tissue debris from the injured area via phagocytosis [42] and by activating satellite cells [43]. Macrophages, which increase in concentration 1-3 days after injury, are thought to contribute to muscle regeneration [11], but also may induce some injury. The beneficial contribution of macrophages to the events associated with muscle regeneration has been ascribed to their ability to phagocytose tissue debris [44] and to their capacity to cause myoblast proliferation in vitro [45]. However, macrophages also have the ability to increase damage in muscle when there is an impaired capacity to generate nitric oxide, which serves to protect muscle membranes [46]. 
The elevation in neutrophils and macrophages in the diaphragm in the present study is consistent with other observations after lengthening contractions of muscle $[47,48]$, electrically stimulated contractions [49] and exposure of muscle to toxin or poison $[41,42]$, but contrary to other recent reports $[50,51]$. Of these two differing reports, one described the extensor digitorum longus (EDL) muscle in response to in situ lengthening contractions [50] and the other investigated the diaphragm in response to resistive loading [51]. The apparently discrepant results by VASSILAKOPOULOS et al. [51] may actually be complementary to the present study and be explained by the different time courses examined. The study by VASSILAKOPOULOS et al. [51] did not find increased myeloperoxidase activity in the diaphragm up to $6 \mathrm{~h}$ after resistive loading in the rat, which may indicate that neutrophils were recruited in the circulation, but did not enter the diaphragm until after $6 \mathrm{~h}$. LAPOINTE et al. [50] concluded that neutrophils in the EDL muscle were not significantly elevated during the hours to days after overt injury caused by lengthening contractions. Alternative explanations for the lack of neutrophil influx in these other two studies [50,51], in contrast to the current study, may be related to differences in species and/or lesser sensitivities in the techniques used to detect neutrophils. CD43, which was used to quantify neutrophils by LAPOINTE et al. [50], may be a less sensitive antibody for labelling neutrophils in skeletal muscle [48]. Furthermore, when a histochemical technique for labelling neutrophils using diamino-benzadine, which illustrates the myeloperoxidase content of granulocytes, was piloted by the current authors, it was found to be less sensitive than using NP-5 to illustrate neutrophil defensin. The present study also differs from some reports of autoimmune muscle diseases, such as polymyositis, where the majority of the inflammatory cells are T-cells. This is not surprising considering the contrasting aetiologies [52].

The IRL sustained by rabbits in this study represents $\sim 60-70 \%$ of the maximal load; a previous report by the present group showed that the maximal diaphragmatic pressure of the rabbit is $\sim 65 \mathrm{cmH}_{2} \mathrm{O}$ during bilateral phrenic nerve stimulation [53]. This load may appear high in terms of clinical relevance, but similar loads to the IRL model may occur during episodes of acute bronchospasm in asthmatics, acute exacerbations of COPD or during weaning trials in mechanically ventilated patients. Patients with stable severe COPD have increased diaphragmatic activation at rest, and $43 \%$ of the maximal electromyogram root-mean square [54], which increases to $81 \%$ during progressive exercise [55]. A major clinical consequence of the inflammatory and injury response of the diaphragm after inspiratory resistive loading is the associated $35 \%$ reduction of its force production shown in earlier work from the current group [15]. Thus, modulation of the inflammatory process during these conditions might facilitate prevention or minimise some of the potential diaphragm injury during these clinical scenarios.

Injury and inflammation in response to an exertional overload of the diaphragm may be part of the normal physiological response of adaptation and repair. In fact, inflammation may be essential to expedite optimal repair, as evidenced by a study in rodents that showed administration of nonsteroidal antiinflammatories resulted in slower regeneration and a weaker myotendinous junction after a partial repair [56]. If diaphragm injury overwhelms the reparative processes, however, injured myocytes may be replaced with connective tissue similar to repetitive strain models of limb muscle injury [57]. Thus, in the event of an overwhelming injury response, carefully timed administration of anti-inflammatories that diminish the injury, followed by agents that increase muscle regeneration may improve clinical outcomes.

One limitation of this study is that an increased ICAM-1 and VCAM-1 expression associated with inflamed, injured diaphragm was observed, but cause and effect were not examined. Future studies are required to identify whether blocking these adhesion molecules would result in less diaphragm injury and/or force loss. A second limitation is the small number of animals in each group and that the IRL group showed a wide variance of VCAM-stained endothelial cells, including three animals who did not show positive VCAM-stained vessels. This variation in VCAM expression may reflect alternative triggers in addition to IRL such as hypoxaemia, or hypercapnia and/or individual differences in susceptibility to diaphragm injury due to factors such as inherent fibre-type characteristics and variable recruitment patterns of inspiratory muscles during IRL.

In conclusion, in this study, inspiratory resistive loading mobilised neutrophils into the circulation with increasing band cell counts, indicating bone marrow release as a major contributor for the increase in circulating neutrophils. Increased surface expression of intracellular adhesion molecule- 1 and vascular cell adhesion molecule-1, and increased infiltration of neutrophils and macrophages/monocytes, are associated with inspiratory resistive loading-induced diaphragm injury and probably mediate muscle injury in this model.

\section{ACKNOWLEDGEMENTS}

The authors would like to thank K. Quinlan for valuable help and A. Scott for technical assistance.

\section{REFERENCES}

1 Yamada M, Suzuki K, Kudo S, Totsuka M, Nakaji S, Sugawara K. Raised plasma G-CSF and IL-6 after exercise may play a role in neutrophil mobilization into the circulation. J Appl Physiol 2002; 92: 1789-1794.

2 McCarthy DA, Dale MM. The leucocytosis of exercise. A review and model. Sports Med 1988; 6: 333-363.

3 Suzuki K, Sato H, Kikuchi T, et al. Capacity of circulating neutrophils to produce reactive oxygen species after exhaustive exercise. J Appl Physiol 1996; 81: 1213-1222.

4 Suzuki K, Totsuka M, Nakaji S, et al. Endurance exercise causes interaction among stress hormones, cytokines, neutrophil dynamics, and muscle damage. J Appl Physiol 1999; 87: 1360-1367.

5 Suzuki K, Yamada M, Kurakake S, et al. Circulating cytokines and hormones with immunosuppressive but neutrophil-priming potentials rise after endurance exercise in humans. Eur J Appl Physiol 2000; 81: 281-287.

6 Nieman DC, Nehlsen-Cannarella SL, Fagoaga OR, et al. Effects of mode and carbohydrate on the granulocyte and monocyte response to intensive, prolonged exercise. J Appl Physiol 1998; 84: 1252-1259. 
7 Suzuki K, Naganuma S, Totsuka M, et al. Effects of exhaustive endurance exercise and its one-week daily repetition on neutrophil count and functional status in untrained men. Int J Sports Med 1996; 17: 205-212.

8 Pizza FX, McLoughlin TJ, McGregor SJ, Calomeni EP, Gunning WT. Neutrophils injure cultured skeletal myotubes. Am J Physiol Cell Physiol 2001; 281: C335-C341.

9 Malm C, Nyberg P, Engstrom M, et al. Immunological changes in human skeletal muscle and blood after eccentric exercise and multiple biopsies. J Physiol 2000; 529: 243-262.

10 Raastad T, Risoy BA, Benestad HB, Fjeld JG, Hallen J. Temporal relationship between leukocyte accumulation in muscles and halted recovery $10-20 \mathrm{~h}$ after strength exercise. J Appl Physiol 2003; 95: 2503-2509.

11 Tidball JG. Inflammatory cell response to acute muscle injury. Med Sci Sports Exerc 1995; 27: 1022-1032.

12 Akimoto T, Furudate M, Saitoh M, et al. Increased plasma concentrations of intercellular adhesion molecule-1 after strenuous exercise associated with muscle damage. Eur J Appl Physiol 2002; 86: 185-190.

13 Goebel MU, Mills PJ. Acute psychological stress and exercise and changes in peripheral leukocyte adhesion molecule expression and density. Psychosom Med 2000; 62: 664-670.

14 Jiang TX, Reid WD, Belcastro A, Road JD. Load dependence of secondary diaphragm inflammation and injury after acute inspiratory loading. Am J Respir Crit Care Med 1998; 157: 230-236.

15 Jiang TX, Reid WD, Road JD. Delayed diaphragm injury and diaphragm force production. Am J Respir Crit Care Med 1998; 157: 736-742.

16 MacGowan NA, Evans KG, Road JD, Reid WD. Diaphragm injury in individuals with airflow obstruction. Am J Respir Crit Care Med 2001; 163: 1654-1659.

17 Muller AM, Cronen C, Muller KM, Kirkpatrick CJ. Heterogeneous expression of cell adhesion molecules by endothelial cells in ARDS. J Pathol 2002; 198: 270-275.

18 De Letter MA, van Doorn PA, Savelkoul HF, et al. Critical illness polyneuropathy and myopathy (CIPNM): evidence for local immune activation by cytokine-expression in the muscle tissue. J Neuroimmunol 2000; 106: 206-213.

19 Howell DC. Statistical Methods for Psychology. 4th Edn. Belmont, CA, Duxbury Press, 1997; pp. 412.

20 Suzuki K, Nakaji S, Yamada M, et al. Impact of a competitive marathon race on systemic cytokine and neutrophil responses. Med Sci Sports Exerc 2003; 35: 348-355.

21 Wigernaes I, Hostmark AT, Stromme SB, Kierulf P, Birkeland K. Active recovery and post-exercise white blood cell count, free fatty acids, and hormones in endurance athletes. Eur J Appl Physiol 2001; 84: 358-366.

22 Kurokawa Y, Shinkai S, Torii J, Hino S, Shek PN. Exerciseinduced changes in the expression of surface adhesion molecules on circulating granulocytes and lymphocytes subpopulations. Eur J Appl Physiol Occup Physiol 1995; 71: 245-252.

23 Benschop RJ, Rodriguez-Feuerhahn M, Schedlowski M. Catecholamine-induced leukocytosis: early observations, current research, and future directions. Brain Behav Immun 1996; 10: 77-91.
24 Vassilakopoulos T, Zakynthinos S, Roussos C. Strenuous resistive breathing induces proinflammatory cytokines and stimulates the HPA axis in humans. Am J Physiol 1999; 277: R1013-R1019.

25 Vassilakopoulos $\mathrm{T}$, Katsaounou $\mathrm{P}$, Karatza $\mathrm{MH}$, Kollintza A, Zakynthinos S, Roussos C. Strenuous resistive breathing induces plasma cytokines: role of antioxidants and monocytes. Am J Respir Crit Care Med 2002; 166: 1572-1578.

26 Nemet D, Hong S, Mills PJ, Ziegler MG, Hill M, Cooper DM. Systemic versus local cytokine and leukocyte responses to unilateral wrist flexion exercise. J Appl Physiol 2002; 93: 546-554.

27 Robertson $\mathrm{CH} \mathrm{Jr}$, Eschenbacher WL, Johnson RL Jr. Respiratory muscle blood flow distribution during expiratory resistance. J Clin Invest 1977; 60: 473-480.

28 Kahoru N, Hirohiko A, Katsuya M, et al. The inhibitory effects of thiopental, midazolam, and ketamine on human neutrophil functions. Anesth Analg 1998; 86: 159-165.

29 Boxer L, Allen J, Baehner R. Diminished polymorphonuclear leukocyte adherence: endothelial cells after stimulation of beta receptors by epinephrine. J Clin Invest 1980; 66: 268-274.

30 Reid WD, Belcastro AN. Time course of diaphragm injury and calpain activity during resistive loading. Am J Respir Crit Care Med 2000; 162: 1801-1806.

31 McCully KK, Faulkner JA. Injury to skeletal muscle fibers of mice following lengthening contractions. J Appl Physiol 1985; 59: 119-126.

32 Salminen A. Lysosomal changes in skeletal muscles during the repair of exercise injuries in muscle fibres. Acta Physiol Scand Suppl 1985; 539: 5-30.

33 Fridén J, Sjöström M, Ekblöm B. Structural and mechanical basis of exercise-induced muscle injury. Med Sci Sports Exerc 1992; 24: 521-530.

34 Frenette J, St-Pierre M, Cote CH, Mylona E, Pizza FX. Muscle impairment occurs rapidly and precedes inflammatory cell accumulation after mechanical loading. Am J Physiol Regul Integr Comp Physiol 2002; 282: R351-357.

35 Muller WA. Leukocyte-endothelial-cell interactions in leukocyte transmigration and the inflammatory response. Trends Immunol 2003; 24: 327-334.

36 Del Maschio A, Zanetti A, Corada M, et al. Polymorphonuclear leukocyte adhesion triggers the disorganization of endothelial cell-to-cell adherens junctions. J Cell Biol 1996; 135: 497-510.

37 Allport JR, Ding $\mathrm{H}$, Collins $\mathrm{T}$, Gerritsen ME, Luscinskas FW. Endothelial-dependent mechanisms regulate leukocyte transmigration: a process involving the proteasome and disruption of the vascular endothelialcadherin complex at endothelial cell-to-cell junctions. J Exp Med 1997; 186: 517-527.

38 Baum M, Liesen H, Enneper J. Leucocytes, lymphocytes, activation parameters and cell adhesion molecules in middle-distance runners under different training conditions. Int J Sports Med 1994; 15: Suppl. 3, S122-S126.

39 Ito $\mathrm{T}$, Kumamoto $\mathrm{T}$, Horinouchi $\mathrm{H}$, et al. Adhesion molecule expression in experimental myositis. Muscle Nerve 2002; 25: 409-418. 
40 Lindvall B, Dahlbom K, Henriksson KG, Srinivas U, Ernerudh J. The expression of adhesion molecules in muscle biopsies: the LFA-1/VLA-4 ratio in polymyositis. Acta Neurol Scand 2003; 107: 134-141.

41 Orimo S, Hiyamuta E, Arahata K, Sugita H. Analysis of inflammatory cells and complement C3 in bupivacaineinduced myonecrosis. Muscle Nerve 1991; 14: 515-520.

42 Papadimitriou JM, Robertson TA, MitchellCA, Grounds MD. The process of new plasmalemma formation in focally injured skeletal muscle fibers. J Struct Biol 1990; 103: 124-134.

43 Seale P, Rudnicki MA. A new look at the origin, function, and "stem-cell" status of muscle satellite cells. Dev Biol 2000; 218: 115-124.

44 Mitchell CA, McGeachie JK, Grounds MD. Cellular differences in the regeneration of murine skeletal muscle: a quantitative histological study in SJL/J and BALB/C mice. Cell Tissue Res 1992; 269: 159-166.

45 Merly F, Lescaudron L, Rouaud T, Crossin F, Gardahaut MF. Macrophage enhance muscle satellite cell proliferation and delay their differentiation. Muscle Nerve 1999; 22: 724-732.

46 Tidball JG. Interactions between muscle and the immune system during modified musculoskeletal loading. Clin Orthop Relat Res 2002; Suppl. 403, S100-S109.

47 Pizza FX, Koh TJ, McGregor SJ, Brooks SV. Muscle inflammatory cells after passive stretches, isometric contractions, and lengthening contractions. J Appl Physiol 2002; 92: 1873-1878.

48 Tsivitse SK, McLoughlin TJ, Peterson JM, Mylona E, McGregor SJ, Pizza FX. Downhill running in rats: influence on neutrophils, macrophages, and MyoD+ cells in skeletal muscle. Eur J Appl Physiol 2003; 90: 633-638.
49 McLoughlin TJ, Tsivitse SK, Edwards JA, Aiken BA, Pizza FX. Deferoxamine reduces and nitric oxide synthase inhibition increases neutrophil-mediated myotube injury. Cell Tissue Res 2003; 313: 313-319.

50 Lapointe BM, Frenette J, Cote CH. Lengthening contraction-induced inflammation is linked to secondary damage but devoid of neutrophil invasion. J Appl Physiol 2002; 92: 1995-2004.

51 Vassilakopoulos T, Divangahi M, Rallis G, et al. Differential cytokine gene expression in the diaphragm in response to strenuous resistive breathing. Am J Respir Crit Care Med 2004; 170: 154-161.

52 Arahata K, Engel AG. Monoclonal antibody analysis of mononuclear cells in myopathies. III: Immunoelectron microscopy aspects of cell-mediated muscle fiber injury. Ann Neurol 1986; 19: 112-125.

53 Jiang TX, Cairns A, Road JD, Wilcox PG. Effect of betaagonist clenbuterol on dexamethasone-induced diaphragm dysfunction in rabbits. Am J Respir Crit Care Med 1996; 154: 1778-1783.

54 Sinderby C, Beck J, Spahija J, Weinberg J, Grassino A. Voluntary activation of the human diaphragm in health and disease. J Appl Physiol 1998; 85: 2146-2158.

55 Sinderby C, Spahija J, Beck J, et al. Diaphragm activation during exercise in chronic obstructive pulmonary disease. Am J Respir Crit Care Med 2001; 163: 1637-1641.

56 Almekinder LC, Gilbert JA. Healing of experimental muscle strains and the effects of nonsteroidal inflammatory medicine. Am J Sports Med 1986; 14: 303-308.

57 Stauber WT, Smith CA, Miller GR, Stauber FD. Recovery from 6 weeks of repeated strain injury to rat soleus muscles. Muscle Nerve 2000; 23: 1819-1825. 